\title{
A Percepção da Educação Ambiental no Ensino de Jovens e Adultos - EJA Escola Estadual Antônio Aggio - São Paulo, Capital
}

\author{
The Perception of Environmental Education in Youth and Adult \\ Education - EJA Public School Antônio Aggio - São Paulo, Capital
}

${ }^{1}$ Ari E. Vicente Silva, ${ }^{2}$ Margarida Marchetto (m_marchetto@ufmt.br)

Recebido: Maio 2015; $\quad$ Avaliado e Aceito: setembro 2015;

Resumo: A Educação Ambiental (EA) decorre de uma percepção renovada de mundo; uma forma integral de ler a realidade e de oferecer a possibilidade de desenvolver projetos, que não somente envolvam e integrem a comunidade escolar, de todas as faixas etárias, mas que também possibilitem a construção de uma ponte, entre escola e comunidade, entre escola e realidade ambiental local e entre escola e vida. O principal objetivo da pesquisa foi avaliar a educação ambiental de jovens e adultos. Desta forma apresentam-se os resultados obtidos com a aplicação de um questionário na Escola Estadual Antônio Aggio em três salas de Educação de Jovens e Adultos - EJA, na região de Santo Amaro São Paulo. Este trabalho visou buscar o conhecimento e o comportamento ambiental dos alunos quanto a percepção da Educação Ambiental inserida em seu currículo. A metodologia utilizada foi baseada na aplicação e análise dos resultados de questionários fechados, totalizando o número de 88 alunos entrevistados no ano de 2012.

Palavras-chave: Visão ambiental, capacitação de jovens e adultos e desenvolvimento sustentável

\begin{abstract}
The Environmental Education (EE) stems from a renewed perception of the world; an integral way to read reality and to offer the possibility of developing projects, that not only involve and integrate the school community, of all ages, but also allow the construction of a bridge between school and community, between school and reality local environmental and between school and life. The main objective of the research was to evaluate the environmental education of youth and adults. Thus, we present the results obtained with the application of a questionnaire in the State School Antonio Aggio in three rooms of Youth and Adult Education - EJA, in Santo A maro São Paulo region. This study aimed to seek knowledge and the environmental performance of students and the perception of environmental education inserted into your curriculum. The methodology used was by application and analyses of closed questionnaires, bringing the number of 88 students interviewed in 2012.
\end{abstract}

Keywords: Environmental vision, training youth and adult and sustainable development.

\section{INTRODUÇÃO}

A Educação de Jovens e Adultos - EJA, como qualquer processo educativo, busca transmitir e gerar novos conhecimentos desenvolvendo uma atitude crítica e criativa quanto ao conhecimento acumulado e devido à realidade socioeconômica, cultural e ambiental em que vivemos. Busca também estabelecer um diálogo entre os saberes e a experiência que jovens e adultos já acumularam e trazem para a sala de aula como parte da sua bagagem intelectual. Nesse contexto é importante a inserção da educação ambiental na vida desses indivíduos, propondo apresentar elementos que irão contribuir para a sua formação como cidadãos conscientes e adeptos de conhecimento sobre as questões ambientais.
Partindo dessa perspectiva, é importante ressaltar que a Educação Ambiental possui uma função estratégica importantíssima dentro e fora da escola. Ela oferece a possibilidade de desenvolver projetos que não somente envolvam e integrem a comunidade escolar, de todas as faixas etárias, mas que também possibilitem a construção de uma ponte, às vezes tão frágil, entre escola e comunidade, entre escola e realidade ambiental local e entre escola e vida. (REIS \& MORAIS pg.1)

De acordo com Cavalcante (2002) o sentido de educar ambientalmente hoje vai além de sensibilizar a população para o problema. Não basta mais apenas saber o que é certo ou errado em relação ao meio ambiente. Precisase até mesmo superar a noção de sensibilizar, que na maior parte das vezes é entendida 
como compreender racionalmente. Só a compreensão da importância da natureza não é suficiente para ser levada a sua preservação. Sensibilizar pessoas envolve o sentimento de amar, ter prazer de cuidar, com o sentido de doação de integração de pertencimento a natureza.

Segundo Ferreira (2008) a educação ambiental se constitui uma forma de educação, que tem como objetivo atingir todos os cidadãos, através de um processo participativo permanente, criando no educando uma consciência crítica sobre as questões ambientais. Essa crítica passa assim a ser vista, como a capacidade de captar a gênese e a evolução de problemas ambientais. Dentro desse contexto, é clara a necessidade de mudar o comportamento do homem em relação à natureza no sentido de promover a compatibilização de práticas educativas, para o melhor conhecimento do mundo.

Conforme Cunha (2005) é preciso ainda e, sobretudo, a mobilização, colocar a ação em movimento, incorporar (razão e emoção) a questão ambiental no cotidiano de nossa ação como prioridade. E uma mudança de atitude nossa com nos mesmo, em uma nova visão de mundo; nossa com os outros e ao ambiente que envolve, em uma ação solidária. E tudo isso em nossa luta política, como seres sociais que somos, pela conquista de um novo modelo de sociedade que preze a relação do equilíbrio com o meio ambiente, que passa obrigatoriamente pela justiça social, ou seja, e a construção de uma nova sociedade ambientalmente sustentável. É preciso, portanto, o exercício pleno de nossa cidadania em um processo de conscientização (consciência + ação)

Para que haja uma sensibilização e entendimento da importância do Meio Ambiente é preciso, antes de tudo, que seja dado ao homem uma Educação Ambiental onde o Meio Ambiente passe a ser visto como fundamental para a vida no planeta, e isso só se pode conseguir através de uma Educação Ambiental efetivada desde a mais tenra idade, através das práticas da própria família e posteriormente, enfatizadas na escola. "Precisamos oferecer mais formação". (DIAS, 2000).
Nesse sentido justifica-se que seja fundamental que um seguimento tão importante na formação do ser, como é a escola busque realizar um trabalho bastante efetivo junto ao educando estendendo essa ação inclusive para os demais membros da comunidade escolar.

Diante disso, segundo Segura (2003),

"A escola representa um espaço de trabalho fundamental para iluminar o sentido da luta ambiental e fortalecer as bases de formação para a cidadania, apesar de carregar consigo o peso de uma estrutura desgastada pouco aberta às reflexões relativas à dinâmica sócio ambiental. Isto não significa, porém, que a EA se limita ao cotidiano escolar. Pelo contrário, cada vez mais se expande para os diversos setores sociais envolvidos na luta pela qualidade de vida".

São necessárias diversas componentes para se atingir todas as dimensões abrangidas pela Educação Ambiental: amor e respeito à vida, interesse e conhecimento acerca do meio ambiente, postura crítica e consciência diante dos próprios hábitos. Uma questão crucial para o sucesso dos programas de educação ambiental é a adoção de ferramentas adequadas para que cada grupo atinja o nível esperado de percepção ambiental.

Dentro da escola deve-se procurar encontrar meios efetivos para que cada aluno compreenda os fenômenos naturais, as ações humanas e sua consequência para consigo, para sua própria espécie, para os outros seres vivos e o ambiente. É fundamental que cada aluno desenvolva as suas potencialidades e adote posturas pessoais e comportamentos sociais construtivos, colaborando para a construção de uma sociedade socialmente justa, em um ambiente saudável

A proposta teve como objetivo principal promover a socialização de informações e estimular ações no intuito de permitir que a comunidade escolar, principalmente educação de jovens e adultos tenham melhor compreensão das causas da degradação ambiental refletindo sobre a participação no processo de preservação do ambiente em que o ser humano passa grande parte do tempo.

Para isso foi necessário desenvolver os objetivos Específicos a seguir:

$>$ Verificar a percepção dos estudantes de Educação de Jovens e Adultos - 
EJA em relação a Educação Ambiental.

Aplicar o Questionário aos alunos. Quantificar os resultados das percepções em percentuais e discutir os resultados.

Analisar os resultados do questionário

Como metas da proposta de Educação Ambiental foi trabalhado a prática educativa que deve contemplar os alunos enquadrados no programa de Educação de Jovens e Adultos (EJA).

$\mathrm{O}$ trabalho fundamentou-se em levantamento de documentação bibliográfica e aplicação de questionário a três salas de EJA da Escola Estadual Antônio Aggio. Pois se entende que a Educação Ambiental não se restringe meramente a trabalhar assuntos relacionados à natureza: lixo, preservação, paisagens naturais, animais, etc. Tem um caráter mais amplo, pois o compromisso é com uma construção de valores e comportamentos e que se propicie ao educando vislumbrar a verdadeira interação entre o ser humano e a natureza.

\section{ÁREA DE ESTUDO}

A pesquisa foi realizada na Escola Estadual Antônio Aggio, localizada na Rua Hercília Gonçalves dos Santos, 16 - Jardim Dulce, São Paulo - Capital, tendo como público-alvo: três classes de estudantes Jovens e Adultos Turma de EJA.

\section{MATERIAL E MÉTODOS.}

Inicialmente foi realizada uma pesquisa bibliográfica, baseada em consultas em livros, anais de congressos, artigos científicos, dissertações e teses publicadas, e fontes pesquisadas em websites.

A pesquisa de campo foi realizada por meio de questionários fechados, aplicado em três classes de alunos matriculados, num total de 88 alunos. Os questionários continham questões que visavam identificar o perfil do entrevistado, a atuação da disciplina Educação Ambiental em suas ações como um futuro profissional e questões associadas à conduta do aluno em relação à variável ambiental. Os dados obtidos foram tabulados e analisados por procedimentos estatísticos descritivos e estão expostos ao longo do texto em forma de gráficos, no item Resultados e discussões.

A proposta foi desenvolvida, com auxílio e envolvimento de professores do curso de EJA, foi elaborado o questionário $\mathrm{e}$ aplicada durante a aula.

A preparação do questionário abrangeu as questões ambientais gerais, resíduos sólidos, disposição dos mesmos, regiões hidrográficas, recursos hídricos, uso e ocupação do solo, qualidade do ar, etc.

O Trabalho envolveu as seguintes etapas: Contatar as turmas de EJA, apresentar o projeto, aplicar o questionário, compilar os resultados, apresentar na forma de gráficos e discutir cada questão.

O questionário contém 17 questões alternativas e de múltipla escolha sobre educação ambiental.

A proposta contribuiu para aumentar a percepção quanto as questões ambientais, para conhecer e entender os estudantes das EJA e saber trabalhar este tema posteriormente.

A intervenção foi realizada por meio da aplicação de questionários, com questões objetiva, visando conhecer as concepções e percepções dos alunos.

\section{RESULTADOS E DISCUSSÕES}

Os dados obtidos com a aplicação dos questionários foram quantificados com $\mathrm{o}$ objetivo de verificar mudanças qualitativas nas concepções dos alunos a respeito dos temas trabalhados. As questões objetivas foram analisadas por porcentagem simples considerando o somatório dos resultados encontrados. De posse desses dados e da análise dos mesmos foi possível obter as conclusões. Estas levaram a inferir sobre o nível de conhecimento relacionado ao tema. Porém, observou-se um grande distanciamento entre as respostas nas três classes testadas.

A Educação Ambiental, neste sentido, é entendida como o processo através do qual o indivíduo e a coletividade constroem valores sociais, conhecimentos, atitudes, habilidades, interesse e competência voltados para a 
conservação do meio ambiente, bem de uso comum do povo, essencial à sadia qualidade de vida e sua sustentabilidade. A Educação Ambiental é uma necessidade e deve ser uma prática que busque a superação da sociedade dominante, a fim de construir e intervir na mudança de comportamento da população e na participação ativa em busca de superação dos problemas sociais, econômicos e ambientais de sua localidade.

A Lei 9.795, 1999, art. $1^{\circ}$ Entende por educação ambiental "os processos por meio dos quais o indivíduo e a coletividade constroem valores sociais, conhecimentos, habilidades, atitudes e competências voltadas para a conservação do meio ambiente, bem de uso comum do povo, essencial à sadia qualidade de vida e sua sustentabilidade".

A incorporação da cultura e da realidade vivencial dos educandos como conteúdo ou ponto de partida da prática educativa é um princípio pedagógico já bastante assimilado entre os que se dedicam à educação básica de adultos. No caso da educação de adultos, talvez fique mais evidente a inadequação de uma educação que não interfira nas formas do educando compreender e atuar no mundo.

$\mathrm{O}$ ensino de jovens e adultos é uma área de práticas e reflexão que de maneira inevitável transpassa os limites da escolarização em sentido estrito. Primeiramente, porque engloba processos formativos diversos, onde podem ser incluídas iniciativas visando a qualificação profissional, o desenvolvimento comunitário, a formação política e inúmeras questões culturais pautadas em outros espaços que não o escolar.

Além disso, mesmo quando se focalizam os processos de escolarização de jovens e adultos, com seus tempos e espaços rigidamente delimitados, imediatamente se apresenta como problemático.

No que concerne as atividades didáticas realizadas com alunos do EJA deve-se evidenciar a experiência de forma significativa para o entendimento da profissão de educador. Este trabalho mostra as desigualdades sociais brasileiras, faz parte um contexto mais recente, em que a educação deve ser inserida em todas as camadas da sociedade, indiferente da idade do cidadão. Com as contradições nas respostas do questionário, nota-se as dificuldades de comunicação e relacionamento de alguns alunos de EJA.

É a partir desse momento, quando lançado mão apenas do conhecimento teórico deve-se atrelá-lo ao prático (vivências) momento que se deve visualizar uma nova forma de educar que vai além do livro, do professor e do aluno. Em prol social, a regência didática desmistifica esse tripé e deve colocar a equipe que está desenvolvendo o estudo numa situação real, numa vivência que só a prática é capaz de ofertar.

Os jovens e adultos participantes desse trabalho mostraram conhecimento prévio, até mesmo experiências vivenciadas sobre os diversos assuntos abordados/discutidos (educação ambiental, Aquecimento global, água e o lixo). Ou seja, vivência e percepção do cotidiano.

Neste trabalho, buscou-se verificar a percepção dos estudantes de EJA da escola citada, observar o conhecimento que possuem sobre as questões que envolvem o ambiente, do que seriam problemas ambientais e, mais especificamente os existentes no bairro em que moram quem seriam os atores sociais causadores desses problemas e quem poderia fornecer as soluções para eles. Além disso, buscou-se conhecer suas práticas em relação à conservação e/ou melhoria do ambiente a que pertencem. A abordagem do questionário teve como início a seguinte questão:

\section{O que se considera como lixo?}

Após a obtenção dos dados com a resposta do questionário os mesmos foram trabalhados graficamente para facilitar a análise, conforme pode ser constatado no Gráfico 1 . Continuando a análise da segunda questão foi elaborada a Gráfico 2. 


\section{Em sua cidade o lixo é coletado e disposto para tratamento em um Aterro Sanitário?}

Gráfico 1 - O que se considera como lixo?

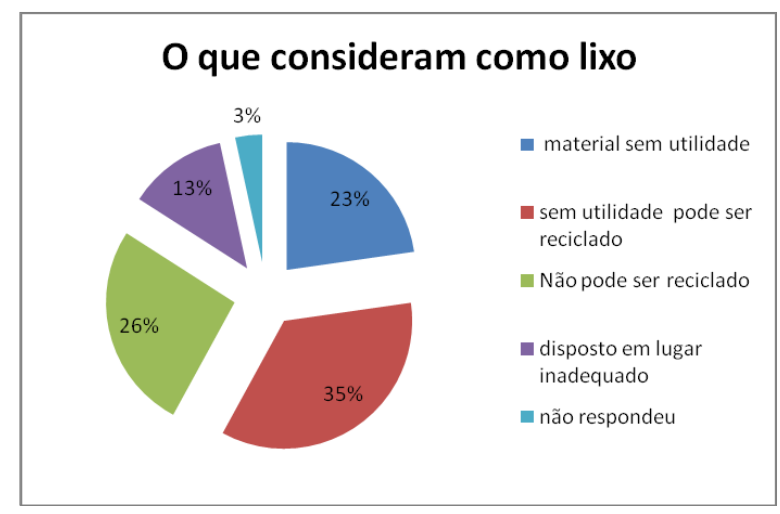

$\mathrm{Na}$ análise dos dados do Gráfico 1 verifica-se que houve dúvidas, pois grande parte respondeu que o lixo é sem utilidade e outra grande maioria considera que o lixo e algo sem utilidade, mas que podem sim ser reciclado, mostrando que falta informação na divulgação dos materiais reciclados. Precisase aprimorar este conceito, deixando de enxergá-lo como uma coisa suja e inútil em sua totalidade. Grande parte dos materiais que vão para o lixo pode (e deveriam) ser reciclado.

$\mathrm{Na}$ análise dos dados do Gráfico 2 verifica-se que a maioria entrevistada tem conhecimento de como são dispostos os resíduos coletados na cidade. Segundo a Constituição Brasileira Gráfico 3 - respostas relacionadas à água.

\section{Em sua casa a água é tratada}

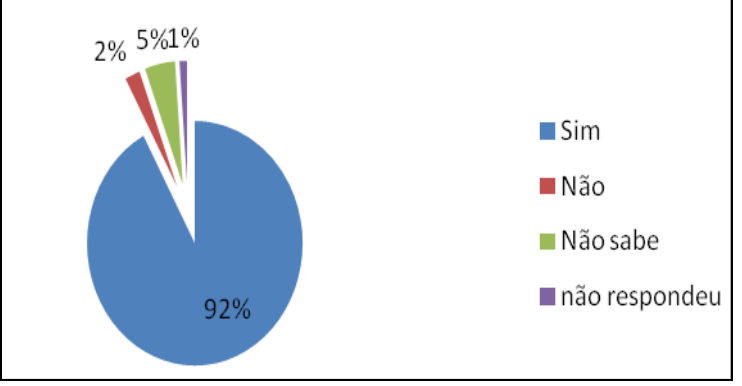

A maioria dos entrevistados, $92 \%$ respondeu que possuem água tratada em sua residência. O Brasil é um dos países onde estão às maiores reservas de água potável do mundo. Mas, ao mesmo tempo, o país consta também da lista daqueles onde se registram os mais altos índices de desperdício. De acordo com o relatório da última reunião do Parlamento Latino Americano, realizada em 2003 no México, o Brasil desvia $40 \%$ da água potável
Gráfico 2- Respostas em relação à coleta de lixo

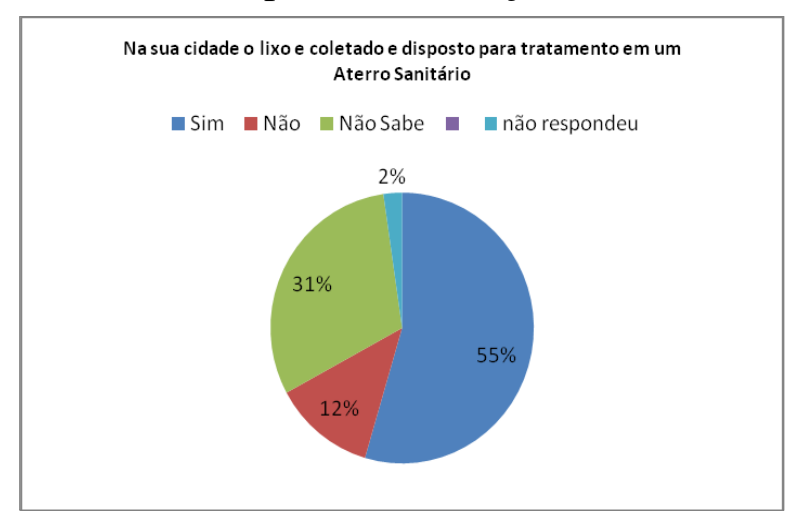

concedeu no município a competência para organizar e prestar os serviços públicos de interesse local, o que expressa sua autonomia administrativa, portanto, prover sobre a limpeza das vias e logradouros públicos, remoção e destino de lixo domiciliar e de outros resíduos, e competência municipal.

No Gráfico 3 foi abordado o tema água, com a seguinte questão: $\mathbf{E m}$ sua casa a água é tratada?

(Gráfico 4) Você de alguma forma ou ação contribui para não desperdiçar a água na sua casa?

Gráfico 4 - Desperdício de água.

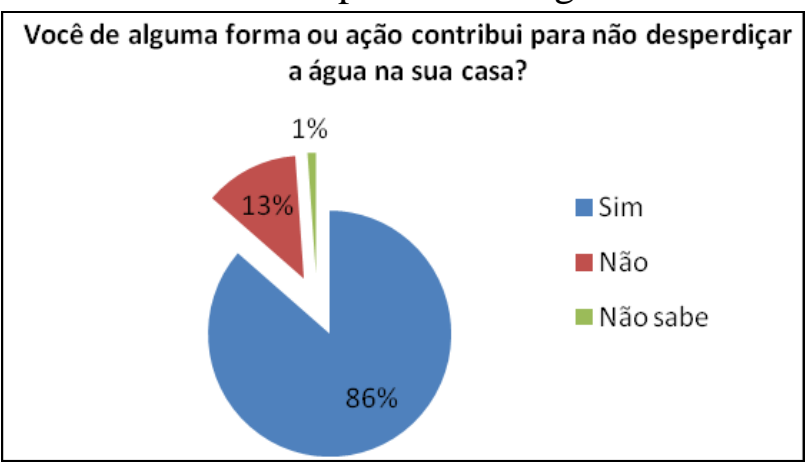

destinada para o consumo humano. A média considerada ideal pela ONU - Organização das Nações Unidas é de 20\%. Na América Latina, apenas Argentina e Chile apresentam índices menores. Disponível em: http://www.jardimdeflores.com.br/ECOLOGIA/A27ve rdadesdaagua.htm

Essa questão é bastante abordada no estado de São Paulo, devido à escassez de água e a elevada população abastecida, o desperdício 
de água poderá trazer várias consequências no bolso da família e sem falar na questão ambiental do planeta. Mesmo assim muitos ainda responderam que não sabem que estão desperdiçando, mesmo com todos os programas disponíveis na mídia televisiva. Segundo SANTOS (2007) é fundamental que o educando desenvolva suas potencialidades e adote posturas pessoais e comportamento sociais construtivos, colaborando para a construção de uma sociedade socialmente justa e um ambiente saudável.

Gráfico 5- Conhecimento de reciclagem.

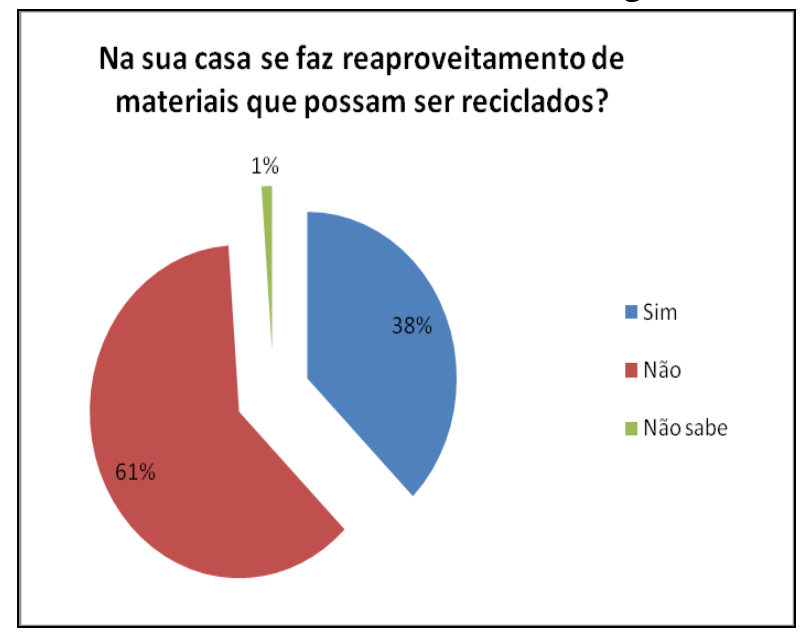

Verificou-se que existia falta de informação quanto aos materiais reciclados e os benefícios que a reciclagem pode trazer a sociedade, $61 \%$ dos entrevistados não reaproveitam os materiais que tem possibilidade de reuso. A prática de reutilizar, além de diminuir os gastos com a limpeza urbana, gera emprego para a população não qualitativa, estimula a concorrência, uma vez que os produtos fabricados a partir dos recicláveis são comercializados em paralelo aqueles feitos a partir da matéria-prima virgem, melhora a produção dos compostos orgânicos, a partir da reciclagem de resíduos orgânicos, portanto que está faltando para o ser humano aprender a cuidar bem do meio ambiente, que ele assuma verdadeiramente uma postura ambiental, um comportamento pró ambiental.

Segundo a Ana Echevenguá, o Instituto Brasileiro de Geografia e Estatística (IBGE) apurou, através da Pesquisa Nacional de Saneamento Básico 2008, divulgada em agosto de 2010, que apenas 50,8\% dos
Em relação à reciclagem de resíduos foi elaborado o Gráfico 5

Na sua casa se faz reaproveitamento de materiais que possam ser reciclados?

Quando perguntado sobre as questões ambientais ocupam cada vez mais espaço nas pautas de discussão da sociedade; mas o que você acha a respeito do assunto? As respostas podem ser conferidas no Gráfico 6.

Gráfico 6- As questões ambientais.

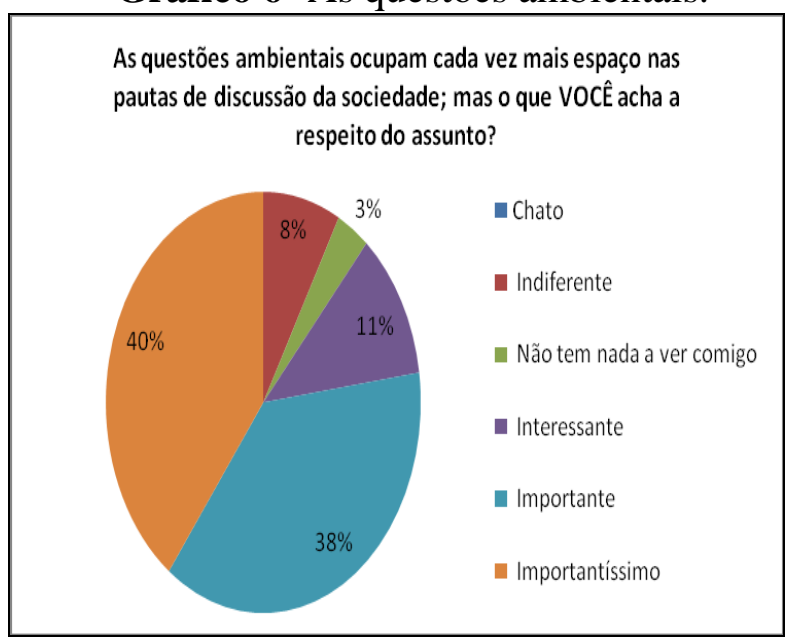

municípios brasileiros dão destinação final adequada aos resíduos sólidos. E que somente $27,7 \%$ usam prioritariamente os aterros sanitários.

As respostas são bastante divergentes e demonstra que os alunos ainda têm certo grau de dificuldade, em identificar esses elementos como problemas ambientais, atualmente, a humanidade está se esquecendo que o meio ambiente é vida. Observa-se que 3\% dos entrevistados responderam que não tem nada a ver com a situação e $8 \%$ se mostra indiferente. Conforme CARVALHO (2004).

Precisa-se ar puro que as árvores nos oferecem, da água limpa tão abundante no mundo, do alimento que a natureza nos dá, entre muitas outras coisas. Tem a lutar pela garantia da vida, da sobrevivência. Da vida dos animais e das espécies vegetais que estão em extinção, da vida existente nos rios, lagos e mares que estão sendo poluídos, das florestas que estão sendo desmatadas, sem o reflorestamento. O Ambiente é a origem da vida, deve-se preservar se a humanidade 
quiser continuar vivendo, por uma questão de cidadania com os semelhantes e justiça com os seres vivos que estão sofrendo sem poder se defender, essa dificuldade pode ser sanada rapidamente com um pouco mais de participação por parte dos professores da rede básica de ensino.

Em relação à questão que tipo de problemas ambientais você percebe que existem na rua ou no bairro onde você mora? O Gráfico 07 demonstra que há uma boa visão da responsabilidade dos próprios moradores em relação aos problemas ambientais do bairro, o governo também leva sua parcela de culpa e, o mais interessante é a percepção da corresponsabilidade moradores/prefeitura em relação à questão ambiental

Gráfico 07 - Respostas dos problemas ambientais rua ou no bairro.

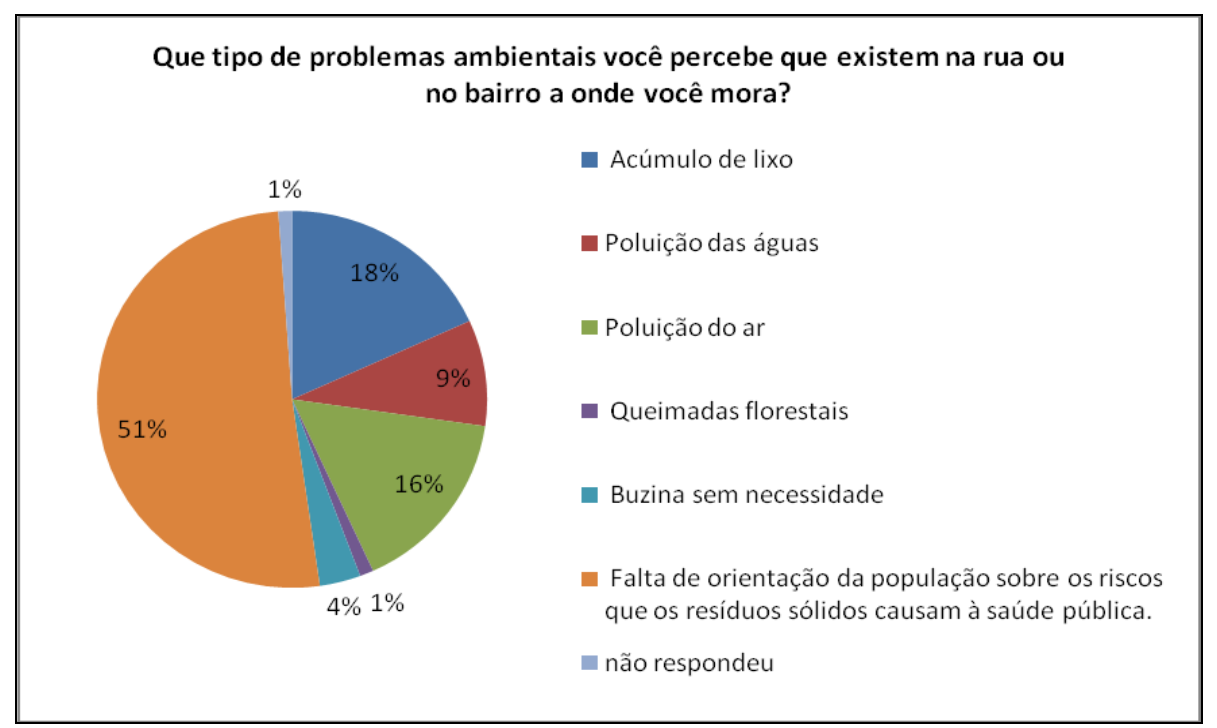

No Gráfico 07 foram relatados os tipos de problemas ambientais, a resposta da coleta de dados os alunos destacavam que em seu bairro $18 \%$ revelam que há acumulo de lixo, o que causa mau cheiro, além de aparecimento de roedores, como também queima de lixo hábitos corriqueiros em bairros, com isso merecendo destaque a poluição do ar, além de problemas respiratórios.

Em relação à poluição, quando questionados. Quais são os tipos de poluição que você considera que seja prejudicial para animais, plantas e seres humanos? A maioria $40 \%$ demonstrou que tem conhecimento, relatando que as poluições da água, do ar, sonoras e visuais são prejudiciais à saúde. (Gráfico 08).

Tipo de poluição que você considera que seja prejudicial para animais, plantas e seres humanos, nessa questão fica bastante claro a dificuldade de destacar um item como prejudicial, nesse item foram destacadas; a Poluição da água, do ar, sonora e visual como sendo a prejudicial aos seres vivos, portanto conforme Santos (2007) O Meio Ambiente é extremamente complexo e, se não nos preocuparmos com as atitudes e comportamentos, estaremos contribuindo para a destruição da nossa geração e das gerações futuras.

No Gráfico 09 em relação à questão de poluição de ar quem você acredita que sejam os maiores responsáveis pela poluição do ar? Dentre as opções, gases lançados a atmosfera mereceu destaque sendo o maior responsável pela poluição do ar nas Cidades. 
Gráfico 8 - Tipos de poluição.

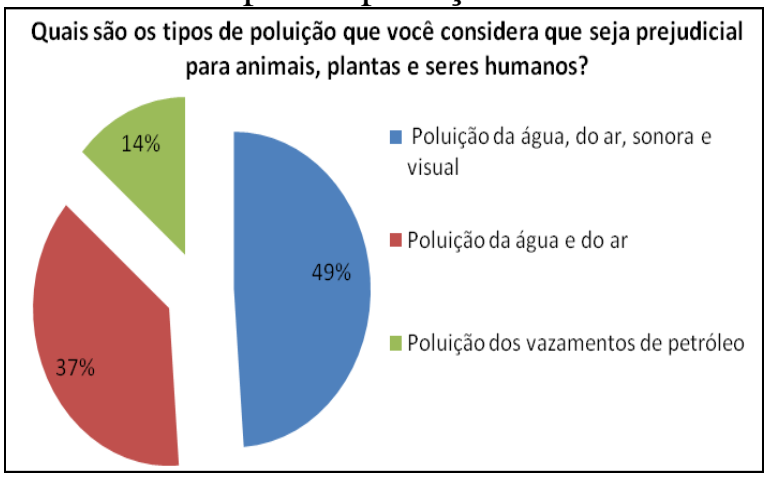

Segundo as literaturas os responsáveis pelo comprometimento da Poluição do Ar são entre outros a grande quantidade de partículas sólidas em suspensão e os gases tóxicos que têm sido lançados na atmosfera, a diminuição dos níveis de oxigênio da atmosfera e a contínua interferência do homem nos ciclos biogeoquímicos, caso não ocorra uma reversão, podem comprometer o futuro das populações animais e vegetais. Em muitos lugares, principalmente São Paulo, a qualidade de vida da população já se encontra seriamente comprometida. Conforme Gráfico 09, verifica-se que os entrevistados estão atentos a esse fator $90 \%$ e se mostrou preocupado com a qualidade do ar, contra $9 \%$ em relação a esgotos, que é um grande problema na destruição do ambiente nas grandes cidades.

No Gráfico 10 é mostrada a resposta da questão você já ouviu falar da necessidade de preservação da Camada de Ozônio?

A percepção que os indivíduos entrevistados têm acerca de seu meio, de acordo com o

Gráfico 10, 79\% se preocupam com essa questão ambiental, existe uma grande dúvida na população em geral com a destruição da camada de ozônio; é uma camada de ar que protege a Terra dos efeitos nocivos do sol a nossa saúde, o contato com esses raios pode provocar sérios problemas a nossa pele como câncer de pele, queimaduras de terceiro grau, e muitos outros problemas.

O que você acredita que seja "Camada de Ozônio"? Foi elaborado o Gráfico 11. Observa-se que a percepção dos estudantes em relação à camada de ozônio ainda precisa ser amadurecida, 5\% não respondeu. Muitos alunos que participaram dessa coleta de dados não tinham conhecimento sobre do que se
Gráfico 09 - Responsáveis pela poluição do ar.

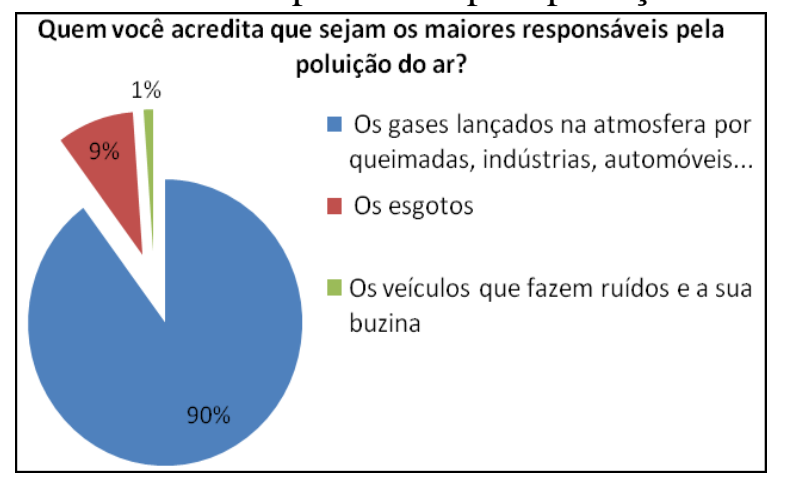

trata a camada de ozônio. Grande parte desses raios que incidem sobre o planeta são nocivos aos seres humanos, responsáveis pela incidência de câncer de pele, problemas de visão, além de provocar a redução da produção agrícola e de alimentos.

Segundo Santos (2007) A camada de ozônio nada mais é do que uma simples e frágil camada de gás que fica em volta da Terra, que protege os animais, os seres humanos, as plantas, e todo o meio ambiente e os seres vivos em geral, por isso a importância da sua conservação, e $6 \%$ dos entrevistados não acreditam que a exposição aos raios ultravioletas pode causar danos a saúde. 
Gráfico 10: Preservação Camada de Ozônio.

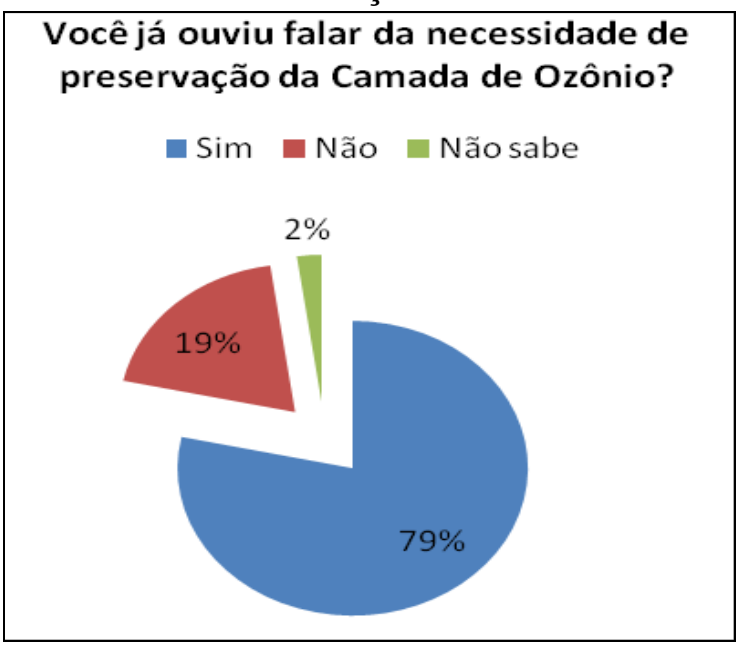

No Gráfico 12 são apresentados os resultados para a questão: Você acredita que a exposição excessiva aos raios ultravioletas pode causar danos à saúde humana?

Gráfico 12 - Exposição aos raios ultravioletas.

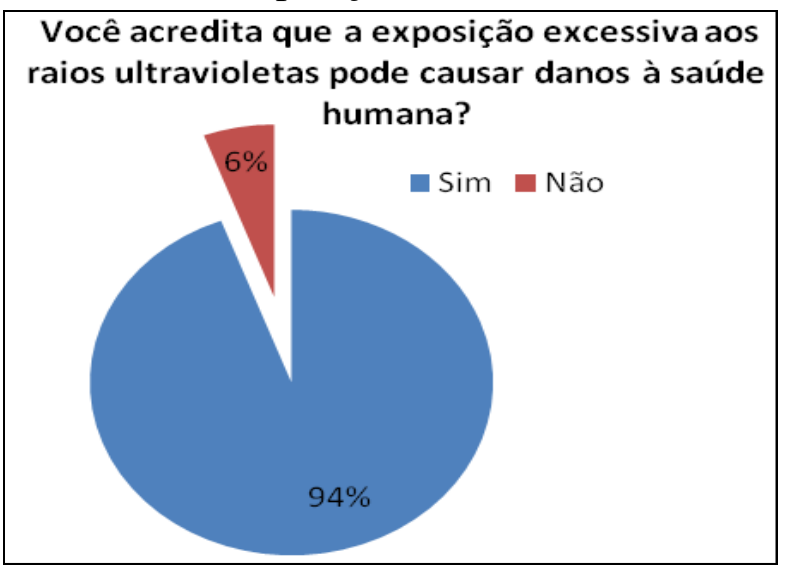

Nesta questão verifica-se que os assuntos são tratados, conforme respondido pela maioria, embora $14 \%$ dos alunos responderam que esses assuntos nunca são tratados, mas as questões referentes ao meio ambientes são trabalhados com intensidade em Feiras de Ciências, ou seja, em períodos de datas comemorativas e eventos promovidos pelas escolas. Portanto, segundo Santos (2005) a preservação ambiental trabalhada de maneira correta nas escolas e com a noção de que não deva ficar restrita apenas ao ambiente escolar, estendendo-se às ruas, poderia contribuir em muito para recuperar e preservar os recursos De quem é a responsabilidade de cuidar ou zelar pelo Meio Ambiente? (Gráfico 15)

Gráfico 11 - Camada de Ozônio ligados ao Meio Ambiente?

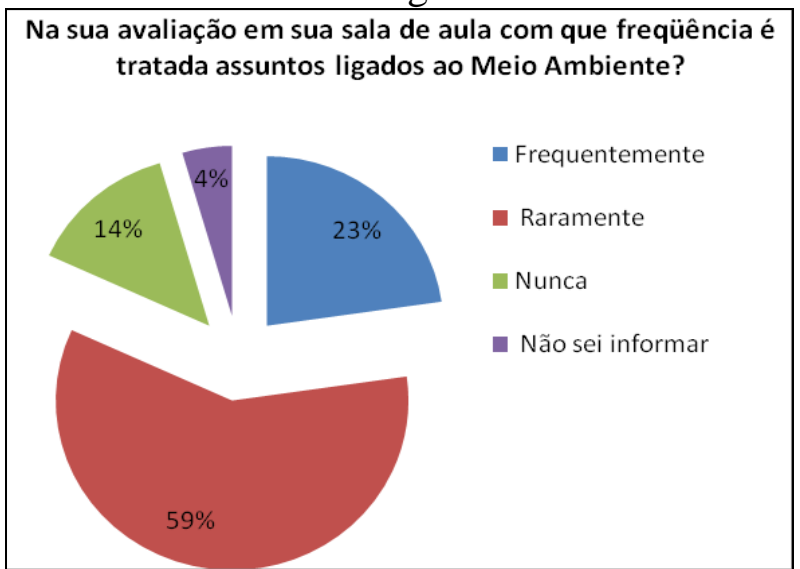
condutas. escola?

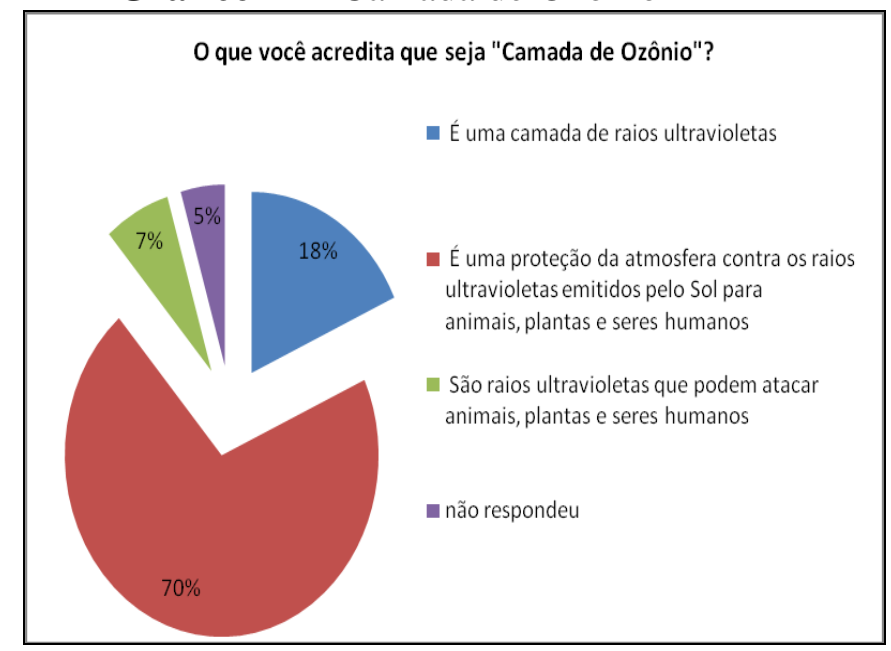

No Gráfico 13 são apresentadas as respostas sobre a avaliação em sala de aula com que frequência é tratada assuntos

Gráfico 13 - Assuntos ligados ao Meio Ambiente.

naturais e melhorar a qualidade de vida da população. Tal situação levaria a sociedade a repensar seus valores, se conscientizando de que os recursos naturais não são infinitos é possível compreender as inter-relações entre o homem e o ambiente, suas expectativas, satisfações e insatisfações, julgamentos e

No Gráfico 14 nas abordagens dos temas ambientais, discutidos em sala de aula deveriam envolver a comunidade em redor da 
Gráfico 14 - Temas ambientais.

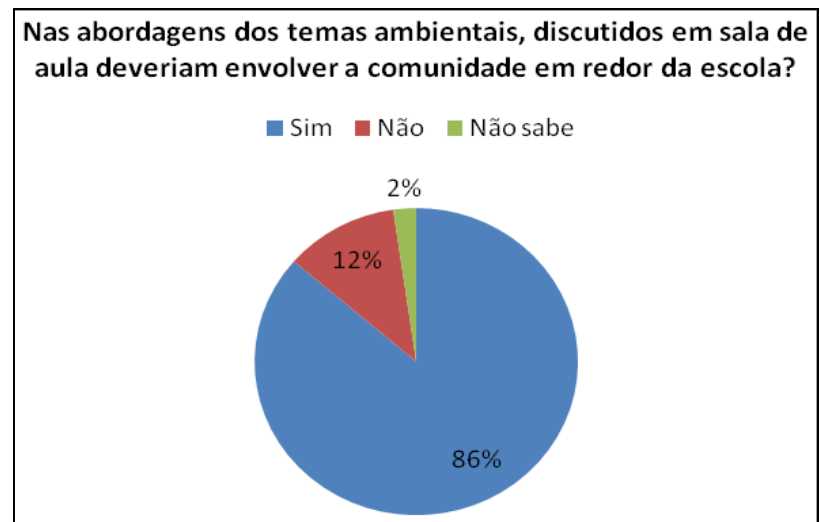

A maioria dos alunos, ou seja, 86\%, respondeu que as abordagens dos temas ambientais, discutidos em sala de aula deveriam envolver a comunidade em redor da escola. $\mathrm{O}$ exercício de uma sociedade participativa poderia ser um caminho para uma sociedade sustentável, que vise uma melhor qualidade de vida no planeta. A maioria dos estudantes $87 \%$ afirmou que a responsabilidade de cuida ou zelar pelo Meio Ambiente é de todos, e já (8\%) respondeu que é da sociedade.

De acordo com o Gráfico 15 toda a população e o governo são responsáveis em cuidar e zelar pelo meio ambiente. Segundo a Constituição Federal/88:

"Art. 225. Todos têm direito ao
meio ambiente ecologicamente
equilibrado, bem de uso comum
do povo e essencial à sadia
qualidade de vida, impondo-se ao
poder público e à coletividade o
dever de defendê-lo e preservá-lo
para as presentes e futuras
geraçôes".

- Precisa-se conscientizar que o ser humano faz parte do meio ambiente, que este não é um todo separado de nós, mas que estamos profundamente conectados a ele e que tudo o que a afeta, de certa forma, nos afeta também.
Gráfico 15- Cuidar ou zelar pelo Meio Ambiente

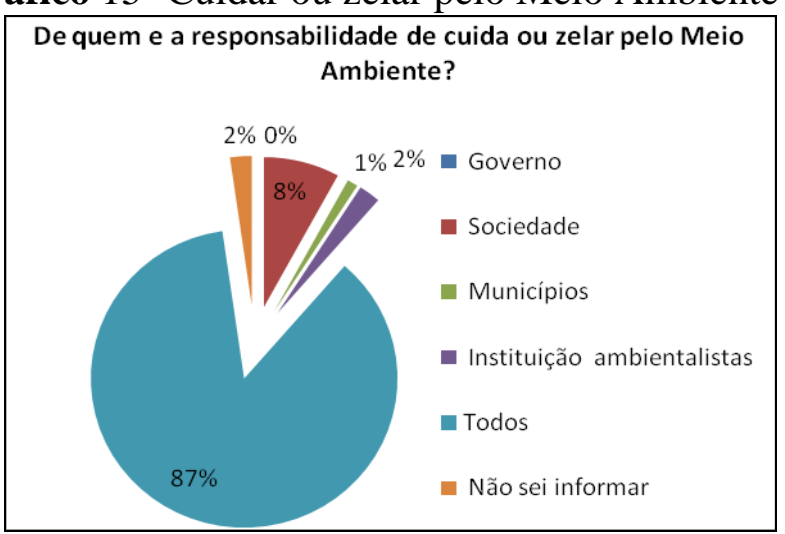

A responsabilidade de zelar pelo meio ambiente é de todos.

Na Figura 16 com a questão: Acredita que possa existir alguma relação entre os níveis de poluição de uma região com a saúde da população?

Quando questionados sobre: Na sua opinião qual dos itens abaixo causa maior agressão ao Meio Ambiente? Figura 17

A grande maioria respondeu que sim, ou seja, $90 \%$, poluição pode ser entendida como qualquer alteração em um meio, de modo a torná-lo prejudicial ao homem e às outras formas de vida que este ambiente normalmente abriga. Assim, qualquer mudança em um ambiente, resultante da introdução de poluentes neste, na forma de matéria ou energia, pode ser entendida como poluição. Geralmente, associa-se a poluição aos malefícios que possam ser causados ao homem(Blanco 2006). No entanto, ela pode resultar em danos a fauna e a flora, e até mesmo ao meio material. Pois falta atitude e conscientização. Esse é um dos maiores problemas que se enfrenta atualmente, dentre outros existentes. A questão é que a cada dia que passa sentimos o resultado dos nossos atos para com o meio ambiente já passou a hora de todos se conscientizar. 
Gráfico 16 - Poluição versus saúde da população.

$\begin{aligned} & \text { Acredita que possa existir alguma relação entre os niveis } \\ & \text { de poluição de uma região com a saúde da população? }\end{aligned}$
$\begin{aligned} & \text { — Nam } \\ & \text { — Não sei } \\ & \text { — Não respondeu }\end{aligned}$

Dentre os problemas citados enfatizaram todos os itens como importantes destacando com 32\% que Lixo não acondicionado é como o principal causador da agressão ao Meio Ambiente, precisa-se ter consciência que esse fato é degradação pontual. Em segundo com $25 \%$ consideram o Desmatamento. Ninguém duvida que o meio ambiente esteja em crise. Mudanças climáticas, derretimento de geleiras, chuvas catastróficas, erosões e tantos outros incidentes avisam que já passou a hora de agir; é preciso correr. Deve-se ter consciência que a natureza ensina, e que tudo o que o homem necessita está disponível, restando apenas ao homem a sabedoria de encontrar as formas equilibradas para prover as nossas necessidades sem provocar 0 esgotamento da fonte, pois são suficientes para a solução das necessidades não só da espécie humana, mas também de todos os seres vivos. Isso requer uma mudança radical na forma de enxergar os elementos naturais.

Os assuntos mais destacados ficaram Lixo não acondicionado, desmatamento, Poluição do ar e das águas, ou seja, a necessidade de urgência de fazer alguma coisa pelo Meio Ambiente, vale lembrar que alguns dos princípios desta abordagem estão na relação entre conteúdos, entre as pessoas, na percepção que todos fazem parte de um sistema uno, na solidariedade, no reconhecimento de que não se precisa de tanto quanto acha-se que precisa, na mudança de paradigmas e valores, etc.

De acordo com Carvalho (2004) O papel do educador é trabalhar pequenas mudanças diárias que podem fazer a diferença na sociedade capitalista que se tem atualmente. A educação ambiental tem papel relevante $\mathrm{e}$ deve estar incluso de modo mais abrangente,

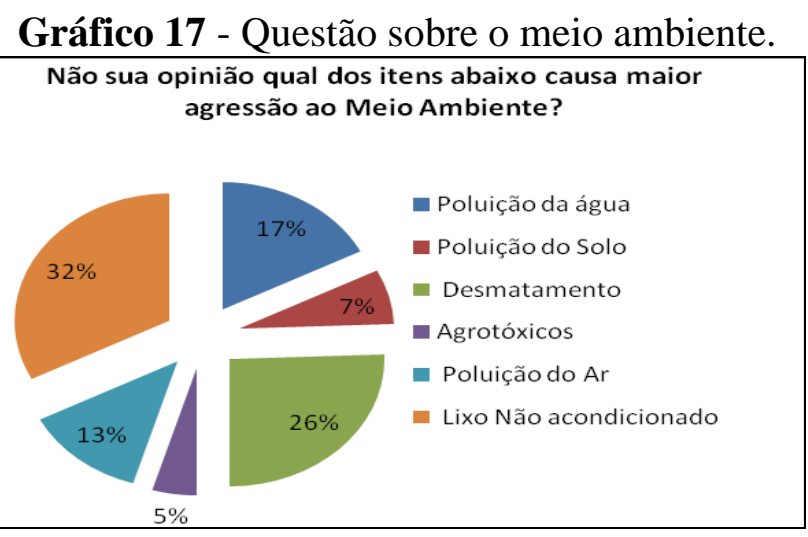

hoje é preciso mudar individualmente para se mudar a coletividade, ou seja, é preciso agir localmente e pensar globalmente, pois a coletividade o principal eixo das grandes mudanças seja elas, sociais, intelectuais e educacionais, o homem precisa aprender a dividir, a sociabilizar principalmente $\mathrm{o}$ conhecimento.

Vale ressaltar que em São Paulo existem pontos de coleta de produtos recicláveis. Em nome de uma cidade melhor, um país melhor, um mundo melhor para nós, nossos filhos, amigos e toda sociedade precisa-se conscientizar da responsabilidade quanto ao lixo produzido e passar esta ideia adiante. A quantidade diária de resíduos sólidos é muito grande e muito desse material é reciclável, vamos fazer a nossa parte.

Observar pontos da cidade endereços para descartar: Pilhas e Baterias de Celulares - Pet e Latinhas - Material Reciclável (Papel, Latas, Vidros, Caixas de Leite E Suco, Jornais E Caixas em Geral). -. Óleo de Cozinha Maxvinil - Material Eletrônico - Fios, Cabos Mouse, Tv, Rádio, Cpu, Vídeos, Etc. - Brasil Reciclagem -Remédios Velhos e Vencidos.

\section{CONCLUSÃO}

O desenvolvimento da pesquisa com aplicação do questionário deve apresentar um cunho satisfatório, possibilitando a sensibilização e a conscientização de alunos. Acredita-se que com a realização deste trabalho com as turmas de EJA, foi possível conhecer melhor o perfil dos mesmos sobre o entendimento e compreensão das causas da degradação do ambiente e poder discutir medidas que poderão ser adotadas para promover mudança de comportamento que 
certamente contribuirá para melhoria significativa da preservação do ambiente. Conseguiu-se cumprir com o objetivo de levantar a percepção das turmas composta por $48 \%$ da sala do sexo masculino e $52 \%$ do sexo feminino e a idade com variação entre 17 a 60 anos. Em relação à educação ambiental no cotidiano escolar, foi possível conhecer a abordagem dada a educação ambiental, como tema interdisciplinar em sala de aula, avaliar o grau de conscientização dos alunos sobre a mesma, assim como a percepção desses sobre o ambiente que os cerca. Além de colaborar com a escola, a fim de os professores poderem trabalhar $\mathrm{e}$ estabelecer abordagem ou visão mais holística aos estudantes, por meio de uma formação que venha modificar atitudes e comportamentos quanto às questões ambientais e contribuir para $o$ desenvolvimento de ações por parte dos estudantes que estimulem a conservação ambiental, promovendo a construção de valores sociais, conhecimentos, habilidades e atitudes no sentido de sensibilizar o cidadão e torná-lo responsável pela conservação do meio ambiente.

Diante dos resultados obtidos com a pesquisa observou-se que os alunos do Projeto para Jovens e Adultos PROEJA possuem conhecimentos intuitivos, adquiridos a partir das suas experiências vividas e a disciplina, embora precisa-se possibilitar mais amadurecimento dos seus valores em relação ao desenvolvimento sustentável, pois os dados mostraram falta de percepção dos estudantes de EJA, precisa-se reforçar o ensino sobre os questionamentos e necessidades do ambiente. Inserir novos conceitos e modificar a percepção errônea de muitos jovens e adultos, com isso espera-se alcançar outros objetivos, tais como, a diminuição do lixo a ser dispensado para os aterros sanitário na cidade; preservação e conservação dos recursos naturais e a formação de uma imagem ecologicamente correta do meio ambiente.

O levantamento da percepção ambiental pode servir como base para os desenvolvimentos de futuros projetos ambientais na escola, pois é possível identificar as dificuldades encontradas, e com isso trabalhar com a realidade local.

Sugere-se que sejam feitas considerações com as três turmas de EJA acerca dos conceitos básicos de educação, meio ambiente e consciência ambiental. Em seguida, os seguintes temas deverão ser abordados de acordo com os seus respectivos focos:

"Educação ambiental": na escola e em casa, englobando jovens e adultos - onde serão abordados os princípios básicos da relação ensino-aprendizagem e práticas ambientais de preservação; "Água, fonte de vida, reserva esgotável? " - Considerações acerca da importância da água para o homem e para o meio ambiente, assim como sua reserva ambiental; e, finalizando a sequência de temas, deverá ser abordado o assunto sobre Destruição e a reconstrução ambiental: "Nós podemos!" - Tema baseado na sétima meta de sustentabilidade ambiental estabelecida pela Organização das Nações Unidas (ONU) para o novo milênio.

Para maior compreensão dos tópicos abordados deverão ser feitas relações entre conteúdo proposto e conteúdo posto em prática através de vivências e simulações em sala de aula com a participação ativa de todos os alunos.

Além disso é possível discutir sobre as possibilidades de:

$>$ Consumir produtos que não agridem ao Meio Ambiente e nem colocam em risco as necessidades das futuras gerações, para se tornar um consumidor consciente basta seguir três princípios básicos: Reduzir, Reutilizar e Reciclar.

$>$ Promover ações que auxiliam no desenvolvimento de atitudes ecologicamente correta, contribuindo para uma formação de consciência ambiental crítica, gerando uma mudança de comportamento e de atitude como:

$>$ Cultivo de hortas e plantas medicinais;

> Montagem de minhocários, aquários;

$>$ Implantação de coleta seletiva na escola; e no bairro; Pontos de entrega voluntária PEV's 
Elaboração de cartilhas e murais ecológicos

Promoções de gincanas ecológicas;

\section{AGRADECIMENTOS}

Os autores agradecem a colaboração dos professores da Escola Estadual Antônio Aggio que colaboraram na pesquisa. A diretora da escola, Maria do Céu B. Góis e a Diretoria de Ensino Sul 2, na pessoa de Maria Neusa Pereira da Silva Machado

\section{REFERÊNCIAS BIBLIOGRÁFICAS}

BLANCO, Guilherme Felipe Entringer Stein Coelho Pereira e, Monografia - Direito Ambiental - Responsabilidade Civil por Danos ao Meio Ambiente e sua Reparação boa, Vilhena, 2006.

BRASIL, Lei 9.795/1999 e o Decreto 4.281/2002 Dispõe sobre a educação ambiental, institui a Política Nacional de Educação Ambiental e dá outras providências. Publicado no D.O.U. de 28.4.1999

CARVALHO, Isabel C. M. Educação Ambiental: A Formação do Sujeito Ecológico, 1a edição, RJ, 2004.

CAVAlCANTE, Clovis (Org.), Meio ambiente, desenvolvimento sustentável e política, $4^{\text {a }}$ edição - São Paulo: Cortez, Recife, Fundação Joaquim Nabuco, 2002.

CUNHA, Sandra Baptista, GUERRA, Antônio José de Teixeira (Organizadores), Impactos ambientais urbanos no Brasil, $3^{\text {a }}$ edição-Rio de Janeiro: Bertrand Brasil, 2005.

CUNHA, Sandra Baptista, GUERRA, Antônio José de Teixeira (Organizadores), A questão ambiental: diferentes abordagens, $2^{\mathrm{a}}$ edição- Rio de Janeiro: Bertrand Brasil, 2005.pag 28 a 40.

CUNHA, Sandra Baptista, GUERRA, Antônio José de Teixeira (Organizadores), A questão ambiental: diferentes abordagens, $2^{\mathrm{a}}$ edição- Rio de Janeiro: Bertrand Brasil, 2005.pag 28 a 40.
DIAS, G.F. Educação ambiental: princípios e práticas. São Paulo, Gaia, 1994.

DIAS, Genebaldo Freire. Educação Ambiental. Princípios e práticas, $6^{\mathrm{a}}$ Edição. São Paulo: Editora Gaia, 2000.

FERREIRA, Wendel Menezes \& OLIVEIRA FILHO, José de. Educação Ambiental: Desenvolvendo Cidadania, Curitiba-PR, 2008.

Disponível em: www.quimica.ufpr.br/eduquim/eneq2008/resu mos/R0101-1.pdf

REIS Layara e MORAIS Márcio Educação Ambiental no Curso Técnico em Edificações do Proeja: Percepção dos Alunos Quanto a Influência da Disciplina no seu Comportamento Ambiental, disponível em: http://www.senept.cefetmg.br/galerias/Anais_2010/Pos teres/GT06/EDUCACAO_AMBIENTAL.pdf

SANTOS, Elaine Teresinha Azevedo dos, Educação Ambiental nas escolas necessidade de conscientização de proteção da camada de ozônio. Ano de 2007. Disponível em: jararaca.ufsm.br/websites/unidadedeapoio/.../e laine07.pdf 